Research Article

\title{
An intensive monitoring of adverse drug reaction in indoor patients of medicine department at tertiary care teaching hospital
}

\author{
Nishita H. Darji ${ }^{1}$, Shilpa Jadav ${ }^{2}$, Chintan Doshi ${ }^{2}$, Rutvij Hedamba ${ }^{2}$, \\ Rusva Mistry ${ }^{2}$, Hiren Trivedi ${ }^{2}$
}

${ }^{1}$ Department of Pharmacology, Smt NHL Municipal Medical College, Ellis-bridge, Ahmedabad, Gujarat, India ${ }^{2}$ Department of Pharmacology, Shri M.P. Shah Government Medical College, Jamnagar, Gujarat, India

Received: 15 February 2016 Accepted: 21 March 2016

\section{*Correspondence to:}

Dr. Nishita Hiteshbhai Darji, Email: nishitadarji@gmail.com

Copyright: () the author(s), publisher and licensee Medip Academy. This is an openaccess article distributed under the terms of the Creative Commons Attribution NonCommercial License, which permits unrestricted noncommercial use, distribution, and reproduction in any medium, provided the original work is properly cited.

\begin{abstract}
Background: Use of drugs itself may result into illness and death due to their adverse effects. In India 10-20\% of inpatients developed adverse drug reactions. Most of these problems can be overcome by undertaking hospital based intensive monitoring. Objective of this study was to estimate the incidence and document the spectrum of ADRs in studied patients in terms of causality, severity, frequency, type and preventability. A prospective, observational, single centre study conducted among the indoor patients of the department of general medicine, Guru Gobind singh government hospital, Jamnagar over a period of 12 months.

Methods: Admitted patients who either had developed a clinically suspected ADR after admission (group A) or were admitted primarily because of an ADR (group B) were included. In all ADR related patients the necessary data was recorded on a pre-designed case record form, NCC-PvPI form and analysis was done.

Results: Total 3566 patients were screened. 87 patients had 101 ADRs, among them 62 from group A and 25 from group B with $2.44 \%$ incidence. In causality, by WHO-UMC and by naranjo scale most common 'probable' category in group A $(54.7 \%)$ and group B (50\%) and $89.9 \%$ group A and $84.6 \%$ in group B respectively.95.05\% ADRs were 'Not preventable'. Hartwig seigle's scale maximum ADRs $65.4 \%$ ADRs in group $\mathrm{A}$ and $73.1 \%$ in group $\mathrm{B}$ were 'moderate' in severity.

Conclusions: Intercurrent illness, longer hospital stay and poly pharmacy was playing a major role in occurrence of multiple ADRs with $2.44 \%$ incidence in our setup.
\end{abstract}

Keywords: ADR, Intensive monitoring, Indoor patients.

\section{INTRODUCTION}

Drugs, no matter how safe and efficacious, are always coupled with inescapable risk of adverse reactions. To overcome this problem, it is important that the ADR monitoring should always be undertaken on a continuous basis. Spontaneous reporting plays a major role in the identification of safety signals but it captures only a small fraction of the adverse events that actually take place (underreporting). ${ }^{1,2}$ There are strong biases in reporting. ${ }^{3}$ These problems can be overcome by undertaking a hospital based intensive monitoring. Hospital as a complex organization, treating very ill patients with multiple simultaneous drugs. Intensive hospital-based monitoring consists of routine prospective recording of drugs administered throughout their hospital stay to detect adverse reactions, whether or not any associations between drugs and events. ${ }^{4}$ This can shed light on their incidence, extensiveness and pattern of occurrence of ADRs in the local population.

\section{METHODS}

After a prior permission from Ethical committee and Head of the Medicine department this prospective, observational, single centre study was conducted among the indoor patients of the department of general medicine, G.G. government hospital, Jamnagar over a period of 12 months. All patients, $>12$ years of age and of both sex were admitted to the medicine units during the study 
period were screened. Visits of medicine units were done daily and screened every patient from admission to discharge. The attending doctors and the nursing staff were appraised about the study objectives and were requested to inform about any adverse drug reactions. The detection of the ADRs was therefore done both by the investigator himself as well as the attending medical and paramedical personnel. For the study purposes the patients were divided into two groups,

Group A Patients that were admitted for other ailments (other than an ADR) but developed the ADRs during hospitalisation and

Group B Those patients that were admitted primarily due to the ADRs that developed outside the hospital.

In all the ADR related patients the necessary data was obtained and recorded on a pre-designed case record form (CRF), NCC-PvPI form and consent was taken in written in inform consent form. The data recorded included the following;

- In CRF form general details e.g., name, age, sex, past and present history, general and systemic examination, laboratory investigation, diagnosis and treatment were noted.

- In a "NCC-PvPI ADR form" which is prescribed by Indian pharmacopoeia commission, details of general patient characteristics, adverse drug event, suspect medication, treatment of ADR and its outcome were noted.

- For ADR assessment, causality analysis by WHOUMC (1972) and Naranjo probability score 5, 6 preventability scale by using the criteria of Schumock and Thornton, Severity scale by Hartwig and Siegel. ${ }^{7,8}$ Besides these major parameters other important heads of analysis were; types and onset of ADRs, ADR categorization according to anatomical system, ADRs distribution according to drug class, seriousness of ADRs, outcome of ADRs.

\section{RESULTS}

Total numbers of 3566 patients were screened during the study period. Of these, 3479 patients had no ADR. Out of the remaining patients, 62 developed the ADRs during hospitalisation (group A) and 25 patients were admitted primarily for the treatment of ADRs that developed outside the hospital (group B). Thus, a total of 87 patients had the ADRs in the study period of 12 months. Thus, the incidence of the ADRs in our study was $2.44 \%(n=3566)$. The data revealed that a total number of 101 ADRs were reported in 87 patients. Among them 75 (74.2\%) were reported in group A and the remaining 26 (25.7\%) were seen in group B.

Majority of the patients that showed the ADRs were in the age group of 31-60 years $(44,50.6 \%)$. The mean age of the patients who developed ADR was 39.7 years. Out of a total number of 3566 patients, 2548 patients were male and the remaining 1018 were female. The incidence of the ADRs in male patients was $1.8 \%(46 / 2548)$ and that was found $4.0 \%,(41 / 1018)$ in case of female patients. The male:female ratio was $1.12 \%$.

Most of the ADRs were of type A which is total 66 $(65.35 \%)$. These ADRs were dose related and the pharmacological reactions that usually subside with stoppage of drug/reduction in dose.

A study of association between the time of drug intake and the onset of ADR showed that most of the adverse drug reactions $85(84.1 \%)$ developed within 10 days of drug intake. Only $12(11.9 \%)$ of the ADRs were reported to have developed after one month of drug administration.

Most of the ADRs, 89 (88.12\%), were resolved within a week after starting treatment. A total of $12(11.88 \%)$ ADRs, however, did not subside and were continuing at the time of discharge. No death was reported due to the ADRs.

ADR categorization according to anatomical system9 large number of ADRs 35 (34.7\%) belonged to gastrointestinal (GIT) and skin $29(28.7 \%)$. This was followed by CNS and blood. The gastrointestinal tract ADRs were mainly, diarrhoea (10), epigastric pain (9), vomiting (5), gastritis (4), metalic taste (3), oral ulceration (2), constipation (1) and gum hypertrophy (1) (Table 1).

Table 1: ADR categorization according to anatomical system ( $\mathbf{n}=101)$.

\begin{tabular}{|ll|}
\hline System & Total ADRs (\%) \\
\hline GIT & $35(34.7)$ \\
\hline Skin & $29(28.7)$ \\
\hline CNS & $15(14.9)$ \\
\hline Blood & $5(4.9)$ \\
\hline Miscellaneous & $5(4.9)$ \\
\hline Respiratory system & $4(3.9)$ \\
\hline Renal & $2(2)$ \\
\hline Ear & $2(2)$ \\
\hline Musculoskeletal & $2(2)$ \\
\hline Endocrine & $1(1)$ \\
\hline Eye & $1(1)$ \\
\hline
\end{tabular}

In group wise distribution of ADRs analysis shows that gastrointestinal ADRs developed most commonly during hospitalisation in group A was 27 (36\%) while gastrointestinal and cutaneous ADRs 8 (30.7\%) were equally the most common cause of hospitalisation in group B (Figure 1).

ADRs distribution according to drug class majority was antimicrobial agents $63(62.4 \%)$ followed by drugs of central nervous system $9(8.9 \%)$ and drugs of cardiovascular system 8 (7.9\%) (Figure 2). 
Suspected medication was usually administered by oral $68(67.3 \%)$ or intravenous route $26(25.7 \%)$. Other routes of administration were found to be uncommon.

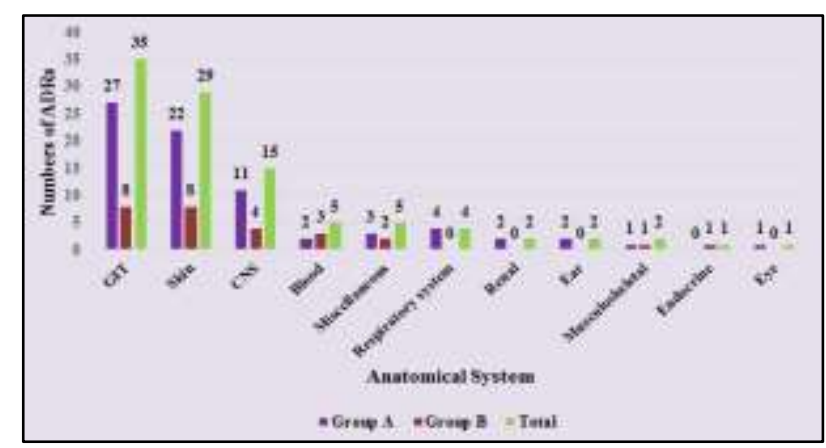

Miscellaneous included chills, Rigor and Ankle oedema.

Figure 1: Group wise distribution of $\operatorname{ADRs}(n=101)$.

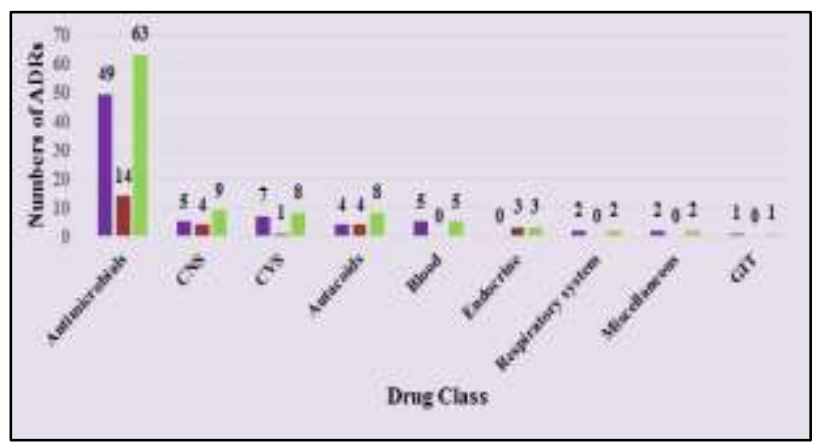

Figure 2: ADRs distribution according to drug class.

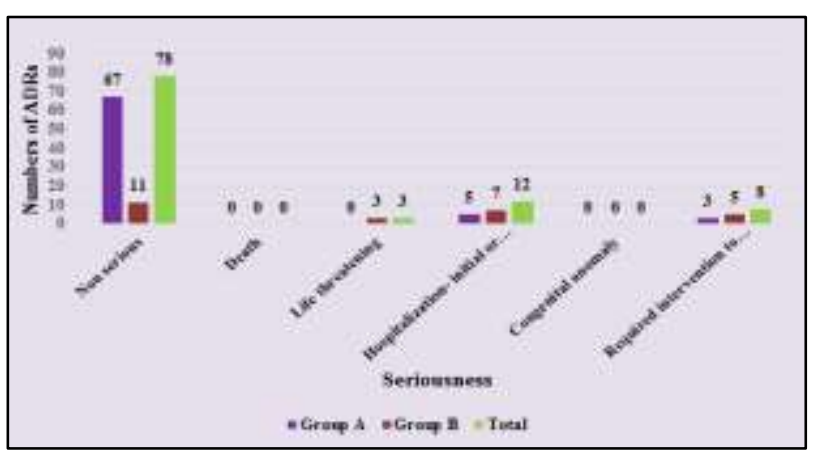

Figure 3: Seriousness of the ADRs.

Adverse drug reactions were categorized as serious or non-serious based on WHO classification. Out of 101 reports, 23(22.8\%) ADRs were considered to be serious and $78(77.2 \%)$ ADRs to be non-serious. We further divided the serious and non-serious ADRs in group A and B. We found that in observed 78 non-serious ADRs 67 $(89.3 \%)$ belonged to group A and $11(42.3 \%)$ in group B. In the same manner, $15(57.7 \%)$ serious ADRs were seen in group B and $8(10.7 \%)$ serious ADRs in group A. (Figure 3) However, we did not encounter any serious ADRs such as death, disability and congenital anomaly in any of the groups. In conclusion, most of the ADRs in group A were non-serious and all those in B were of serious nature.

Regarding Outcome of ADRs in group A 49 (65.3\%) of ADRs were in recovered category while in group B 19 $(73 \%)$ of ADRs were in recovering phase. Considering total ADRs, out of total 101 ADRs 53 (52.5\%) ADRs were recovered which were maximum in number.

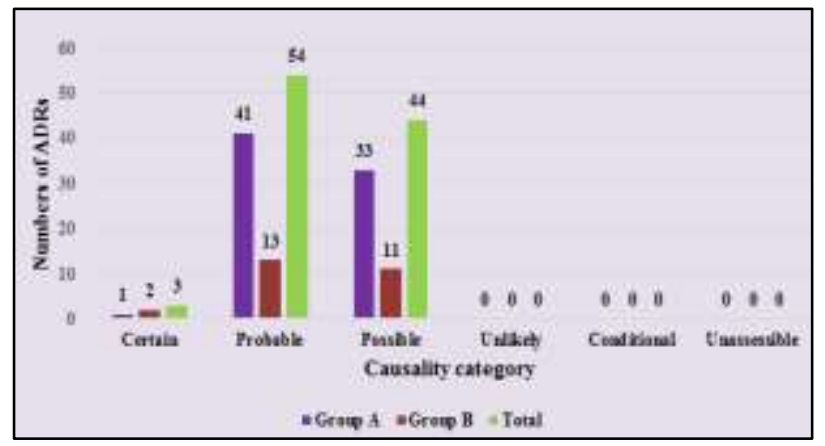

Figure 4: WHO-UMC causality criteria.

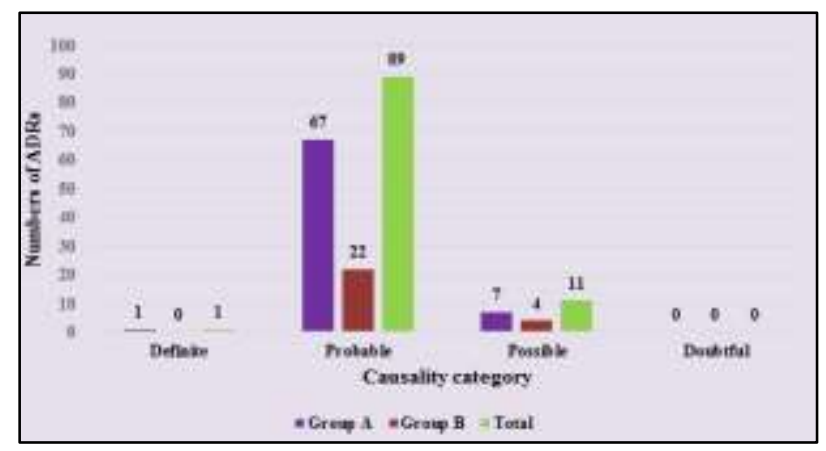

Figure 5: Naranjo's causality scale.

The causality assessment of the ADRs was carried out using both the WHO-UMC criteria (Figure 4) and Naranjo's scale (Figure 5) which showing majority of ADRs were under 'probable' category that was 54 $(53.5 \%)$ and $89(88.1 \%)$ respectively. A closer scrutiny of results underlined the fact that even in the individual categories of 'probable' and 'possible', the results were slightly more varied amongst group A than group B. Thus revealed that the majority of the cases $41(54.7 \%)$ were probable and $33(44 \%)$ cases were possible in group A in WHO-UMC criteria and these were $67(89.3 \%)$ and 7 (9.3\%) respectively in Naranjo's scale.

Out of the total of $5(4.95 \%)$ preventable ADRs by Schumock and Thornton scale, majority 3 (11.5\%) belonged to group B and only a small number $2(2.7 \%)$ to group A. ${ }^{7}$ Total $96(95.05 \%)$ ADRs were not preventable and from them $73(97.3 \%)$ belonged to group A and 23 $(88.5 \%)$ belonged to group B. Out of a total number of 26 ADRs that causes the hospital admission in patients of group B, $88.5 \%$ were not preventable. 


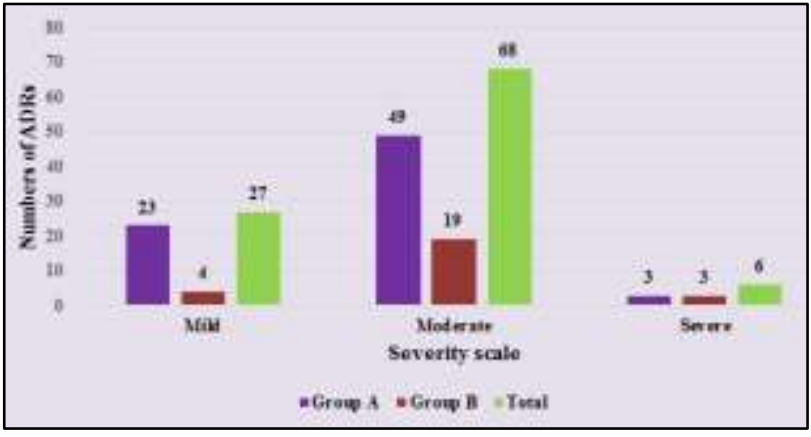

Figure 6: Severity scale of ADRs (modified hartwig and siegel).

In severity of ADRs by Hartwig and Siegel scale majority of ADRs $68(67.3 \%)$ were moderate in severity (Figure $10) .{ }^{8}$ A total number of $6(6 \%)$ ADRs were severe in nature. Out of 68 moderate ADRs, we observed 49 $(65.4 \%)$ ADRs in group A and $19(73.1 \%)$ ADRs in group B (Figure 6).

\section{DISCUSSION}

We have detected the incidence of ADRs to be $2.4 \%$ of the patients. This is slightly less than what has been observed in other Indian and foreign studies. In a couple of Indian study Ramesh $\mathrm{M}$ et al, and Foreign study WA Tumwikirize et al the incidence recorded were $4.4 \%$ and $6 \%$ respectively. ${ }^{10,11}$ Most of these studies had taken into account either the total hospital admissions or all the patients admitted to particular specialities (for example, medicine, TB and chest etc.). However, it is possible that patients receiving certain special groups of drugs, e.g., anticancer and anti-tubercular medications were also included in these studies. These drugs are likely to produce a greater number of adverse drug reactions and therefore a higher incidence is likely to be recorded.

We observed that majority $50.6 \%$ of our patients belonged to the age group of 31-60 years and around $12.6 \%$ of the patients belonged to geriatric age group (>60 years). This is an agreement with Ramesh $M$ et al 200310 who also observed that around $67 \%$ of the patients were adults and nearly $30 \%$ belonged to geriatric age group. North brazil study, MG Lobo, et al also reported that nearly $61 \%$ of the patients showing ADRs in their study belonged to the adult age group. ${ }^{12}$ Our study has provided a further support to this observation.

We have observed that higher number of incidence of ADRs $(4 \%)$ in females in this study. In a very large study conducted in South India, R Arulmani et al a higher incidence of ADRs has been reported for females $8.7 \% .^{13}$

We have seen that predominantly the ADRs observed in group A and group B was type A (65\%). Most of the other studies like Uganda study, WA Tumwikirize et al have reported a higher percentage of type A reactions $99.5 \%$ which is also support to our study. ${ }^{11}$
In our study majority of patient had onset of ADRs within 1 day which is $56.4 \%$ and this data is comparable to south-Indian study, R Arulmani et al which is $55.5 \%$ as supportive to study. ${ }^{13}$

The present study has shown that most commonly reported ADRs occurred at gastrointestinal tract (34.7\%), skin and central nervous system in that order. A number of authors have reported nearly the same observations in studies by Javedh shareef et al, Jose J, Rao PGM, Arulmani R, Rajendran SD et al. ${ }^{13,15,16}$ We have also observed that most of the ADRs that lead to hospitalisation (in patients of group B) belonged to skin and GIT. This is also in agreement with others study, MG Lobo et al, Wasserfallen JB et al, Capuano A et al. ${ }^{12,17,18}$ It should be noted here that most of the suspected medications are administered by oral route and GIT falls an easy prey to all such medications. Moreover, establishment of a time relationship can be done easily in case of gastrointestinal adverse drug reactions. Adverse effects on skin are also easily noticeable and reported quickly by the patients. The actual incidence of these ADRs may vary from study to study because of several factors like disease and drug use pattern, ethnic, race and genetic influences.

We have further observed that Antibiotic agents (62.4\%) are a frequent cause of adverse drug reactions followed by drugs acting on CNS, CVS and Autacoids in that order. Our findings are in agreement with Javedh shareef et al, Gor AP et al and MG Lobo et al studies conducted in India and abroad (Table 3). ${ }^{12,15,19}$

Antimicrobial drugs are among the most frequently prescribed drugs in the hospital and to a great extent the large amount of their use may be considered injudicious. They are, therefore, quite likely to be the most common offending agents. Very few patients in our study had tuberculosis or HIV/AIDS because these patients were referred to TB ward and ART centre. These patients were admitted solely for the management of the ADRs due to anti-tubercular or antiretroviral drugs and not for the primary management of these disorders. Hence, we did not observe many ADRs due to anti-tubercular drugs or anti-retroviral therapy.

In our study, Specific in group A most common gastrointestinal system ADRs (36.5\%) seen and in group B most common skin ADRs $(29.6 \%)$ and this data comparable to MS. Doshi, et al study in which group A most common GIT ADRs (18.9\%) and in group B most common skin ADRs (13.6\%). ${ }^{4}$

We have seen total $77.2 \%$ of ADRs were non-serious in nature. Among them group A shown maximum nonserious ADRs $(89.23 \%)$ and group B shown maximum serious ADRs (57.7\%). This is in accordance with MS. Doshi, et al study in which group A most common nonserious ADRs $(69 \%)$ and in group B most common serious ADRs $(100 \%)^{4}$ 
We have observed that in WHO-UMC criteria majority of the ADRs in group A and group B were 'Probable' $(88.1 \%)$ which is comparable to Gor AP, et al study $(61.1 \%) .{ }^{19}$ However, we have further seen that in Naranjo scale in both the groups, 'Probable' were maximum and that is in accordance with MS. Doshi, et al study. ${ }^{4}$ Each of these two methods of causality assessment have their own peculiar characteristics. We have, however, experienced that the WHO-UMC method is simple and less time consuming. On the other hand, the Naranjo scale covers many more aspects of ADR profile but it is subjective. (Alternate causes, placebo effects, past history, blood concentration of drug etc.).

Majority of the ADRs (67.3\%) observed by us were moderate in nature in severity scale. Comparison between both the group A and group B severe ADRs were most commonly seen in group B patients that is in accordance with MS. Doshi et al study. ${ }^{4}$ Northen brazil study, MG Lobo et al. ${ }^{12}$

We feel that our study has generated a useful data particularly in the Indian context. This helps to prevent the undesirable drug effects and to undertake the right steps in the right direction. Our study however had a few shortcomings also. Thus, although our sample size was reasonably big it could still have been bigger to achieve a greater accuracy. Our study was limited to the medical units only while it would have been ideal to cover all sections of the hospital. We feel that the duration of the study was adequate as it was able to cover all the seasons in a year. Patients suffering from tuberculosis and HIV/AIDS were very few in our study. We feel that all such patients should be a matter of separate inquiry.

\section{CONCLUSION}

Intercurrent illness, longer hospital stay and poly pharmacy will play a major role in occurrence of multiple adverse drug reactions. Group distributions in our study tell us about percentage of ADRs during hospitalization and ADRs as a causative agent for hospitalization. On the basis of that we can aware the people and prevent the hospitalization due to ADRs which is frequently comes in our study from people of rural area. Continuous motivation and creating awareness among the healthcare professionals for reporting suspecting adverse drug reactions will help to continue reporting and improving the patient safety.

Funding: No funding sources Conflict of interest: None declared

Ethical approval: The study was approved by the Institutional Ethics Committee

\section{REFERENCES}

1. Pirmohamed M, Breckenridge AM, Kitteringham NR, Park BK. Adverse drug reactions. BMJ. 1998;316:1295-8.
2. Dikshit RK, Desai CK, Desai MK. Pleasures and pains of running a pharmacovigilance center. Indian $\mathbf{J}$ Pharmacol. 2008;40(1):31-3.

3. Mann RD, Andrews EB. Pharmacovigilance. Second Edition. John Willey and Sons, Ltd.: England; 2007:7.

4. Doshi MS, Patel PP, Shah SP, Dikshit RK. Intensive Monitoring of adverse drug reaction in hospitalised patients of two medical units at tertiary care hospital. Journal of Pharmacology Pharmacotherapeutics. 2012;3(4):308-313.

5. The use of the WHO-UMC system for standardized case causality assessment. Available at http://www.who umc.org/graphics/4409.pdf. Assessed 2012.

6. Naranjo CA, Busto U, Sellers EM, Sandor P, Ruiz I, Roberts EA, et al. A method for estimating the probability of adverse drug reactions. Clin Pharmacol Ther. 1981;30(2):239-45.

7. Schumock GT, Thornton JP. Focusing on the preventability of adverse drug reactions. Hosp Pharm.1992;27:538.

8. Hartwig S, Seigel J, Schneider PJ. Preventability and severity assessment in reporting adverse drug reactions. Am J Hosp Pharm. 1992;49:2229-32.

9. Guidelines for the ATC classification and DDD assignment, 2013, $16^{\text {th }}$ edition;. Available at www.whocc.no. Assessed 26 August 2013.

10. Ramesh M, Pandit J, Parthasarathi G. Adverse drug reactions in a south Indian hospital- their severity and cost involved. Pharmacoepidemiology Drug Safety. 2003;12:687-92.

11. Tumwikirize WA, Ogwal-Okeng JW, Vernby A, Anokbonggo WW, Gustafsson LL, Lundborg SC. Adverse drug reactions in patient admitted on internal medicine wards in district and regional hospital in Uganda. African health sciences. 2011;11(1)72-8.

12. Lobo MG, Pinheiro SMB, Castro JGD, Gomes V, Cristina SM. Pranchevicius. Adverse drug reaction monitoring, support for pharmacovigilance at tertiary care hospital in Northen Brazil. 2013;14:5.

13. Arulmani R, Rajendran SD. Suresh B. Adverse drug reaction monitoring in a secondary care hospital in south India. BR J Clin Pharmacol. 2008;65(2): 210-6.

14. Hurwitz N, Wade OL. Intensive hospital monitoring of adverse reactions to drugs. BMJ. 1969;1:531-6.

15. Javedh S, Midhun V, Shastry CS. A Prospective study on adverse drug reaction in medicine department. American journal of pharmatech research. 2013;3(6):507-17.

16. Jose J, Rao PG. Pattern of adverse drug reactions notified by spontaneous reporting in an indian tertiary care teaching hospital. Pharmacol. Res. 2006;54:226-33.

17. Wasserfallen J, Livio F, Buclin T, Tillet L, Yersin B, Biollaz J. Type, and cost of adverse drug reactions in emergency admissions. European Journal of Internal Medicine. 2001;12(5):442-7.

18. Capuano A, Motola G, Russo F, Avolio A, Filippelli A, Rossi F, et al. Adverse drug events in two 
emergency departments in Naples, Italy: an observational study. Pharmacological Research. 2004;50:631-636.

19. Gor AP, Desai SV. Adverse drug reactins (ADR) in the inpatients of medicine department of a rural tertiary care teaching hospital and influence of pharmacovigilance in reporting ADR. Indian $\mathbf{J}$ Pharmacol. 2008;40(1):37-40.

Cite this article as: Darji NH, Jadav S, Doshi C, Hedamba R, Mistry R, Trivedi H. An intensive monitoring of adverse drug reaction in indoor patients of medicine department at tertiary care teaching hospital. Int J Basic Clin Pharmacol 2016;5:742-7. 